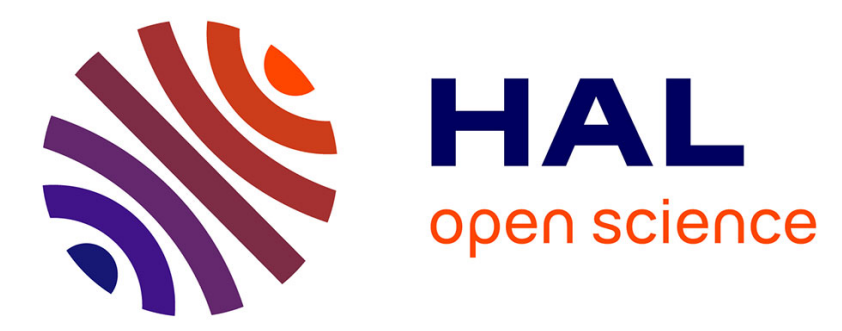

\title{
Use of Gracile and semi-tendinosus tendons (GRAST) for the reconstruction of irreparable rotator cuff tears
}

Marie Protais, Maxime Laurent-Perrot, Mickaël Artuso, M. Christian Moody, Alain Sautet, Marc Soubeyrand

\section{- To cite this version:}

Marie Protais, Maxime Laurent-Perrot, Mickaël Artuso, M. Christian Moody, Alain Sautet, et al.. Use of Gracile and semi-tendinosus tendons (GRAST) for the reconstruction of irreparable rotator cuff tears. BMC Musculoskeletal Disorders, 2021, 22, pp.331. 10.1186/s12891-021-04197-6 . hal03192573

\section{HAL Id: hal-03192573 \\ https://hal.sorbonne-universite.fr/hal-03192573}

Submitted on 8 Apr 2021

HAL is a multi-disciplinary open access archive for the deposit and dissemination of scientific research documents, whether they are published or not. The documents may come from teaching and research institutions in France or abroad, or from public or private research centers.
L'archive ouverte pluridisciplinaire HAL, est destinée au dépôt et à la diffusion de documents scientifiques de niveau recherche, publiés ou non, émanant des établissements d'enseignement et de recherche français ou étrangers, des laboratoires publics ou privés. 


\title{
Use of Gracile and semi-tendinosus tendons (GRAST) for the reconstruction of irreparable rotator cuff tears
}

Marie Protais ${ }^{1 *}$ (D), Maxime Laurent-Perrot ${ }^{1}$, Mickaël Artuso ${ }^{1}$, M. Christian Moody ${ }^{2}$, Alain Sautet ${ }^{1}$ and Marc Soubeyrand ${ }^{3}$

\begin{abstract}
Background: Irreparable rotator cuff tears are common and difficult to treat. Techniques for "filling the loss of substance" require fixation to the rotator cuff stump (tendon augmentation) or to the glenoid (superior capsular reconstruction), which are complicated by the narrow working zone of the subacromial space. The main objective of this study was to determine whether a braided graft of gracilis (GR) and semitendinosus (ST) could fill a loss of tendon substance from an irreparable rupture of the supra- and infraspinatus, by fixing the graft to the greater tuberosity and the spine of the scapula.

Methods: This was a cadaveric study with the use of ten specimens. The GRA and ST tendons were harvested, braided and reinforced with suture. An experimental tear of the supraspinatus (SS) and upper infraspinatus (IS) retracted at the glenoid was made. The GRAST transplant was positioned over the tear. The transplant was attached to the greater tuberosity by two anchors and then attached to the medial third of the scapular spine by transosseous stitching. The percentage of filling obtained was then measured and passive mobility of the shoulder was assessed. We proceeded to the same technique under arthroscopy for a 73 years old patient whom we treated for a painful shoulder with irreparable cuff tear. We inserted a GRAST graft using arthroscopy.

Results: The Braided-GRAST allowed a 100\% filling of the loss of tendon substance. Mobility was complete in all cases.

Conclusion: This technique simplifies the medial fixation and restores the musculo-tendinous chain where current grafting techniques only fill a tendinous defect. The transplant could have a subacromial "spacer" effect and lower the humeral head. The donor site morbidity and the fate of the transplant in-vivo are two limits to be discussed. This anatomical study paves the way for clinical experimentation.
\end{abstract}

Keywords: Irreparable rotator cuff tear, Arthroscopy, Gracilis, Semitendinosus

\footnotetext{
* Correspondence: protais.marie@gmail.com

'Département de chirurgie orthopédique et traumatologique - Hôpital

Saint-Antoine, Assistance Publique - Hôpitaux de Paris (APHP), 184 rue du faubourg Saint Antoine, 75012 Paris, France

Full list of author information is available at the end of the article
}

C C The Author(s). 2021 Open Access This article is licensed under a Creative Commons Attribution 4.0 International License, which permits use, sharing, adaptation, distribution and reproduction in any medium or format, as long as you give appropriate credit to the original author(s) and the source, provide a link to the Creative Commons licence, and indicate if changes were made. The images or other third party material in this article are included in the article's Creative Commons licence, unless indicated otherwise in a credit line to the material. If material is not included in the article's Creative Commons licence and your intended use is not permitted by statutory regulation or exceeds the permitted use, you will need to obtain permission directly from the copyright holder. To view a copy of this licence, visit http://creativecommons.org/licenses/by/4.0/ The Creative Commons Public Domain Dedication waiver (http://creativecommons.org/publicdomain/zero/1.0/) applies to the data made available in this article, unless otherwise stated in a credit line to the data. 


\section{Background}

The rotator cuff has two functions: to rotate the head of the humerus (and consequently the whole upper limb) in the three planes of space [6] and to coapt the humeral head against the glenoid [8] .

With aging, degenerative tears are frequently encountered. This cuff tear generally begins in the anterior part of the supraspinatus and then gradually extends to the infraspinatus [2].

Due to the effect of muscular contraction, the tendon stump progressively retracts towards the glenoid. If not used, the muscle then undergoes atrophy and fatty degeneration [13]. When fatty infiltration and retraction are too great, it is no longer possible to bring the ruptured tendon back to its humeral insertion: the tendon is then irreparable [11]. Different surgical options then exist, some of which consist of filling the loss of tendinous substance. These filling techniques are technically complex, especially when performed using arthroscopy. In fact, they require fixation to the cuff stump (tendon augmentation) [4, $20,21]$ or to the glenoid (superior capsular reconstruction) [14] in a subacromial space that is often times quite narrow (Fig. 1).

Some authors have proposed to perform this filling either with autologous grafts such as fascia lata [12], quadricipital tendon [20], allografts [10], xenografts [15] or synthetic matrices [3].

However, these different grafts have important limitations such as the morbidity of the harvest, the inadequate thickness of the graft, the immunological or infectious risk, and the cost.

In order to overcome these limits, we propose a reconstruction technique of the cuff which is original for two reasons.

The first lies in the choice of grafts used and their preparation method. We have chosen to combine the use gracilis (GRA) and semitendinosus (ST) tendons by braiding them to form the GRAST graft. The removal of these tendons has low morbidity and they are usually sizable [1]. The aim of braiding is to construct a graft thickness comparable to the cuff.

The second point of originality is the attachments locations of the graft from the humerus to the spine of the

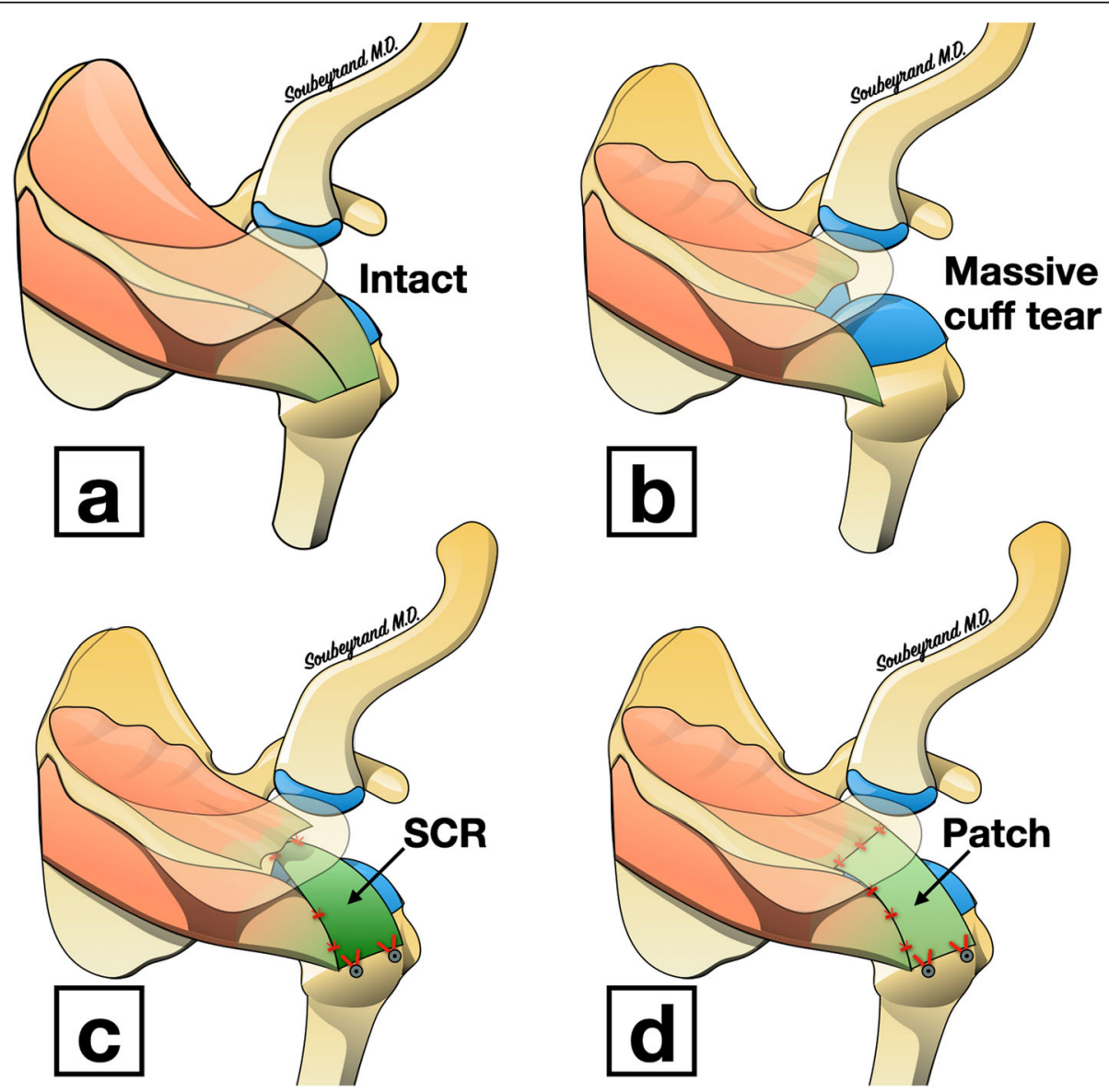

Fig. 1 Intact rotator cuff (a), rotator cufftear (b) and the different options for filling the tear: Superior Capsular Reconstruction (SCR) (c) and the interposition patch (d) (images belong to the author Marc Soubeyrand) 
scapula. This avoids complex fixation procedures to the stump or glenoid in the narrow subacromial space. Fixation to the scapular spine is also technically less demanding because it is practically subcutaneous.

The main objective of this study was to determine whether a GRAST transplant can fill a tendon defect from an irreparable rotator tear of the supra- and infraspinatus, while being long enough to reach the spine of the scapula and the greater tuberosity of the humerus.

\section{Methods}

This was a cadaveric study on ten specimens. The mean age at death was 78 years (72-91). Exclusion criteria were the presence of shoulder stiffness, deformity or signs of prior surgery. The study protocol was approved by our institutional review board (Comité Scientifique et Ethique de l'APHP) and was registered under the CNIL (Commission Nationale de l'Informatique et des Libertés) number $13810^{*} 01$. Anatomical subjects were used in accordance with the willingness to donate one's body for teaching and medical research, expressed in writing during the donor's lifetime. The subjects came from the Fer à Moulin Institute, 7 rue du Fer à Moulin, 75005, Paris, France, Assistance Publique des Hôpitaux de Paris (APHP). We proceeded to the same technique under arthroscopy for a 73 years old patient whom we treated for a painful shoulder with irreparable cuff tear. We inserted a GRAST graft using arthroscopy. The participant gave her informed written consent for the surgery, the submission and the publication of images in Fig. 6a, b, c, d, e.

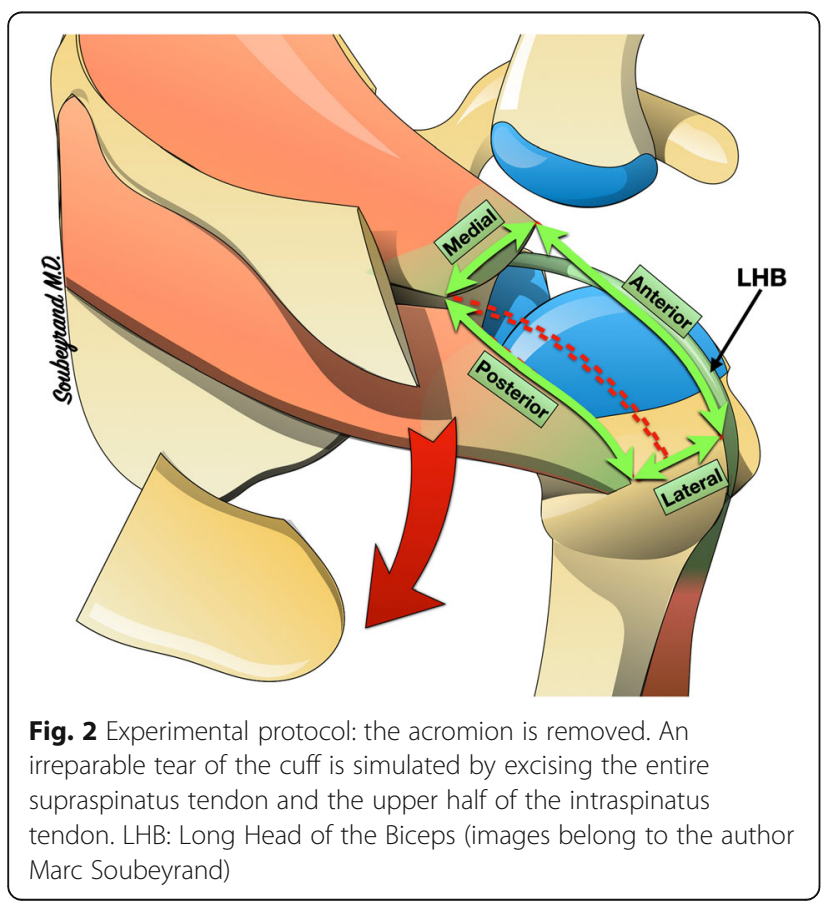

\section{Experimental protocol}

Subject was seated in a beach chair position, one shoulder and one knee in the field. The GRA and the ST were first harvested (Fig. 2) through a vertical skin incision, 2 $\mathrm{cm}$ inwards and $2 \mathrm{~cm}$ below the tibial tuberosity. The GRA and ST were identified below the sartorius fascia and then harvested using a tendon stripper.

Once the two tendons had been harvested, they were placed parallel to each other and folded in half so that both tendons were the same length on each side. The result was four strands and a plication. Two traction sutures (Fibertape ${ }^{\ominus}$ and TigerTape ${ }^{\oplus}$, Arthrex) were placed one centimeter apart and passed through the plicature. The graft was prepared by braiding the 4 strands to obtain the final GRAST graft.

The dry GRAST was then measured with a digital caliper: thickness, width, length and dry volume. The transplant was then preserved in a saline cup.

After 10 min of soaking in saline, the same dimensions were measured again on the wet GRAST.

The shoulder was then approached by a superolateral approach to perform an acromionectomy first. The experimental tear was then induced by excising the entire supraspinatus tendon and the anterior part of the infraspinatus from their humeral insertion to the glenoid, thus simulating an irreparable tear. The dimensions of this defect were measured: antero-posterior, mediolateral (Fig. 2).

The GRAST transplant was then positioned over the loss of substance and fixed with two anchors to the great tuberosity, as in a single-row repair. A suture is then passed from the remaining infraspinatus tendon and attached to the graft allowing the graft to cover the entire empty footprint left by the tear as well as incorporate the intact infraspinatus tendon into the repair. (Fig. 3). The medial end of the graft was brought to the point of fixation on the spine of the scapula. It was considered long enough if the graft was at least $1 \mathrm{~cm}$ longer than the point of fixation on the spine. This excess length of $1 \mathrm{~cm}$ seemed to us to be the minimum length necessary for correct scapular fixation (Fig. 4).

At the end of the procedure, the loss of residual material from the rotator cuff not covered by the graft was evaluated, as well as the percentage of antero-posterior and medio-lateral filling.

Each measurement was repeated twice by two doubleblind operators.

\section{Results}

The average length of the semitendinosus (ST) was 263 $\mathrm{mm}(\sigma=28, \min =210, \max =300)$, that of the gracilis was $240 \mathrm{~mm}(\sigma=34, \min =200, \max =260)$. 


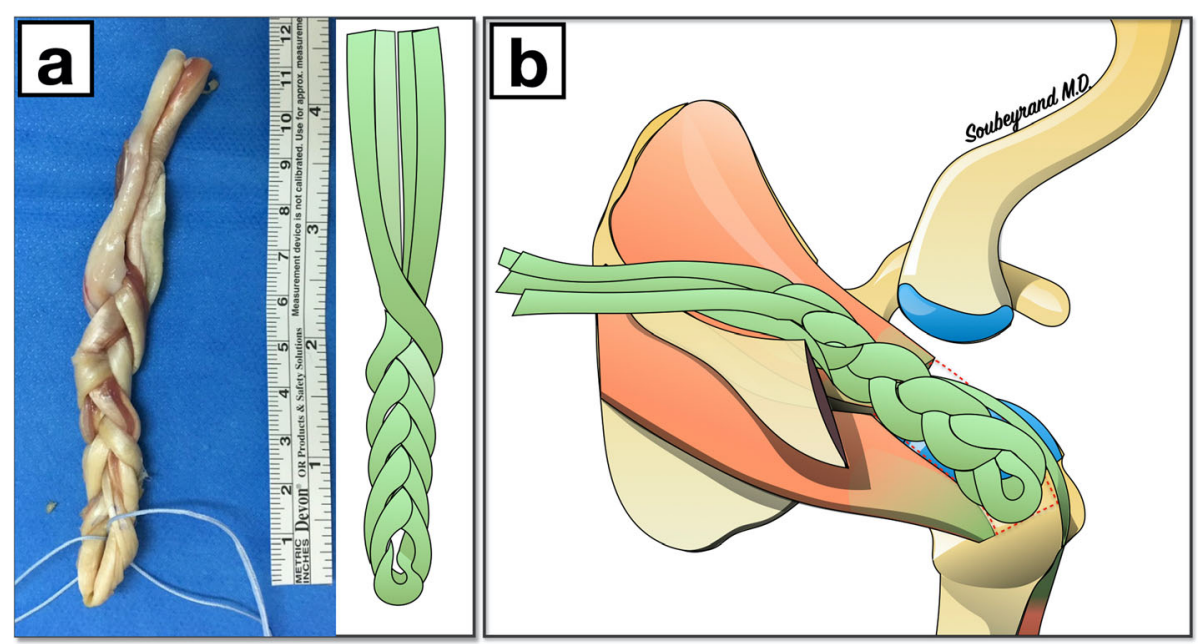

Fig. 3 a The GRAST graft (b) Positioning of the GRAST graft over the tear zone of the cuff and in the supraspinatus fossa. (images belong to the author Marc Soubeyrand)

The dry graft averaged $114 \mathrm{~mm}$ long $(\sigma=18, \min =80$, $\max =130), 13.6 \mathrm{~mm}$ wide $(\sigma=1.26$, $\min =12, \max =16)$, and $5.8 \mathrm{~mm}$ thick $(\sigma=2,8, \min =4,7, \max =11)$.

The average hydrated transplant was $110 \mathrm{~mm}$ long $(\sigma=21, \min =86, \max =136), 15.6 \mathrm{~mm}$ wide $(\sigma=2.98$, $\min =11.7, \max =18.7), 7.7 \mathrm{~mm}$ thick $(\sigma=3.28, \min =$

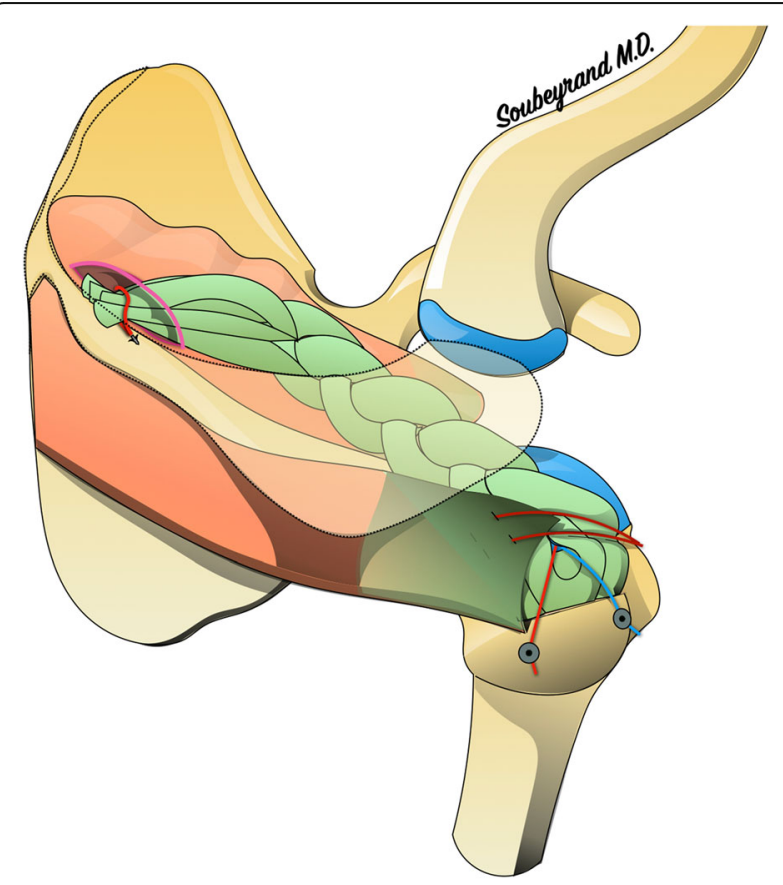

Fig. 4 The principle of the GRAST technique. The GRAST is fixed to the humerus and the residual infraspinatus tendon is fixed over the GRAST. The other end of the GRAST is attached to the scapular spine. (images belong to the author Marc Soubeyrand)
4.7, $\max =12.4)$. When its dimensions were reduced to a parallelepiped, there was an $85 \%$ increase in volume. (Table 1).

The cuff tear was $25 \mathrm{~mm}$ wide $(\sigma=81, \min =18.4$, $\max =40)$ and $34 \mathrm{~mm}$ long $(\sigma=28, \min =30, \max =$ $39.3)$, i.e. an area of $853 \mathrm{~mm} 2(\sigma=238, \min =647, \max =$ 1225) in a rectangle (Table 2). The braided graft filled the entire tear for all the cadavers, and the transplants was passing through the remaining cuff.

In all cases the graft length was sufficient to connect the major tuberosity of the humerus and the spine of the scapula.

During the arm elevation manoeuvres we observed that the GRAST was driven by the humerus towards the supraspinatus fossa. Its passive mechanical behavior therefore does not seem to impinge on the greater tuberosity under the acromion.

The procedure under arthroscopy was simple and took $74 \mathrm{~min}$ in total. We encountered no difficulty for the harvesting and the preparation of the graft. We inserted under arthroscopy the braded GRAST into the supraspinatus fossa throw a posteromedial approach via a short incision on the spine and then threaded medially to

Table 1 Characteristics of the Braided GRAST

\begin{tabular}{lll}
\hline & Before soaking in saline & After soaking in saline \\
\hline Lengh $(\mathrm{mm})$ & $\begin{array}{l}114(\sigma=18, \min =80, \\
\max =130)\end{array}$ & $\begin{array}{l}110(\sigma=21, \min =86, \\
\max =136)\end{array}$ \\
Width $(\mathrm{mm})$ & $\begin{array}{l}13,6(\sigma=1,26, \min =12, \\
\max =16),\end{array}$ & $\begin{array}{l}15,6(\sigma=2,98, \min =11,7, \\
\max =18,7)\end{array}$ \\
$\begin{array}{l}\text { Thickness } \\
(\mathrm{mm})\end{array}$ & $\begin{array}{l}5,8(\sigma=2,8, \min =4,7, \\
\max =11)\end{array}$ & $\begin{array}{l}7,7(\sigma=3,28, \min =4,7, \\
\max =12,4)\end{array}$ \\
$\begin{array}{l}\text { Total volume } \\
(\mathrm{mm} 3)\end{array}$ & $\begin{array}{l}827(\sigma=1952, \\
\min =5472, \max =11,440)\end{array}$ & $\begin{array}{l}15,203(\sigma=10,800, \\
\min =4069, \max =30,042)\end{array}$ \\
\hline
\end{tabular}


Table $\mathbf{2}$ Characteristics of the rotator cuff tear

\begin{tabular}{ll}
\hline Lengh $(\mathbf{m m})$ & $\mathbf{2 5}(\boldsymbol{\sigma}=\mathbf{8 1}, \boldsymbol{m i n}=\mathbf{1 8 , 4}, \max =\mathbf{4 0})$ \\
\hline Width $(\mathrm{mm})$ & $34(\sigma=28, \min =30, \max =39,3)$ \\
Surface $(\mathrm{mm})$ & $853(\sigma=238, \min =647, \max =1225)$ \\
\hline
\end{tabular}

laterally through the supraspinatus stump using the strips that serve as tractor strands. These same strips were finally used for attachment to the major tuberosity by two anchors. The tension was simply adjusted when attaching to the spine under visual control, with the arm along the body. In addition, a tenotomy of the biceps and an acromioplasty were performed.

\section{Discussion}

Our study shows that it is possible to completely fill the void left by an irreparable rotator cuff tear with a GRAST graft. The braiding of the GRAST makes it possible to reproduce the morphology of the torn tendon in all three dimensions of the space, all the better when the GRAST is hydrated (as is the case once it is implanted, especially under arthroscopy). The GRAST graft was able to connect the greater tuberosity of the humerus to the spine of the scapula in all cases. Finally, the passive mechanical behavior of the GRAST does not interfere with the elevation of the arm.

Our technique offers an intermediate solution between superior capsular reconstruction, which has become the primary treatment in many centers in the management of irreparable posterosuperior tears [14], along with partial repair with medialization [5] when the patient is not eligible for a reverse shoulder arthroplasty or tendon transfer. It simplifies medial fixation and restores the musculo-tendinous chain where current grafting techniques are limited with completely filling a tendon defect. In fact, extending the graft to the supraspinatus fossa also offers the hope of incorporation into the body of the muscle.

Centering the head of the humerus in the glenoid is an essential prerequisite for the proper function of the shoulder, especially with forward elevation. Indeed, this allows the center of rotation of the humeral head to be maintained in an optimal position so that contraction of the deltoid causes rotation of the humeral head rather than proximal migration. In addition, it induces a tension effect on the deltoid fibres, which potentiates its strength when the elevation movement is initiated. The natural tendency of the humeral head is to migrate proximally under the action of the powerful deltoid. In the
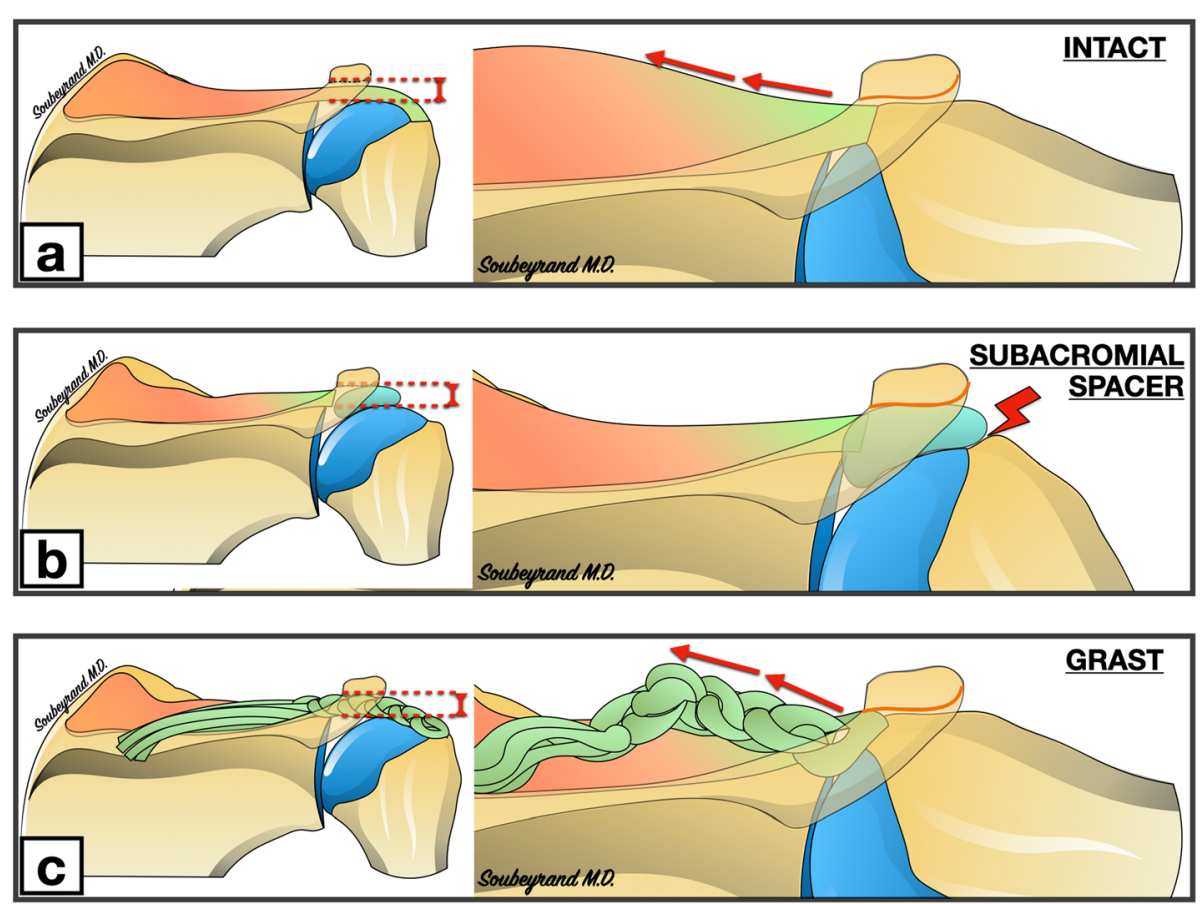

Fig. 5 The subacromial height (red dotted lines) must be maintained when the arm is alongside the body. However, when the arm is raised, the greater tuberosity abuts the lower edge of the acromion and the subacromial height becomes almost zero. a When the arm is in neutral position next to the body, the supraspinatus tendon helps to maintain the subacromial height. When the arm is raised, the tendon escapes towards the supraspinatus fossa, leaving the place for the greater tuberosity. $\mathbf{b}$ Example of the subacromial spacers that maintain subacromial height when the arm is alongside the body. They may interfere with the course of the greater tuberosity when the arm is elevated because they remain in the subacromial space. $\mathbf{c}$ the GRAST graft has a mechanical action similar to that of the supraspinatus tendon. (images belong to the author Marc Soubeyrand) 
event of a massive tear in the cuff, this results in a reduction of the subacromial space. Since glenohumeral congruence is poor, only soft tissues (ligaments, tendons) can oppose this migration. As in many other anatomical sites, there are two complementary solutions to prevent migration of a bone piece in a given direction: "traction" in the opposite direction and "abutment". Traction is usually based on a ligament and/or tendon whose force vector is in the opposite direction to the movement to be prevented. This is similar to the cable of an anchor that prevents the boat from drifting under the action of the current. The stop, on the other hand, consists of placing an obstacle that will oppose the migration of the bone piece. In the shoulder, the only stop between the humeral head and the acromion is the supraspinatus tendon. It has therefore been suggested that proximal migration of the humerus could be prevented by sliding a subacromial spacer implant. This is the case for example with subacromial balloons [16, 17]. However, when the arm is raised, the greater tuberosity will engage under the acromion and the subacromial space will become almost obsolete. If this space is already occupied by a subacromial spacer, the course of the greater tuberosity will be blocked because it will come into abutment with the spacer. The same structure that keeps the humerus at a distance from the acromion when the arm is in the lowered position must therefore be able to be gradually moved out of the way when the arm is raised, without blocking the course of the greater tuberosity. This is exactly what the supraspinatus tendon does. Our study confirms that during passive elevation of the arm, the GRAST graft gradually escapes from the subacromial space into the supraspinatus fossa. (Fig. 5).

However, this study is a cadaveric study and therefore has certain limitations.

As with any anatomical study, the question of in vivo transposition arises. Indeed, one legitimate question is the clinical tolerance of such a transplant as well as the biological fate of the transplant. It is obviously too early to report the results of a clinical series, but a first look at early results can be seen with the case of a 73 years old patient whom we treated for a painful shoulder with irreparable cuff tear. We inserted a GRAST graft using arthroscopy. At 1 year's follow-up, the graft appeared well incorporated with a reconstructed cuff appearance. Clinically, only intermittent residual pain persists, and it is interesting to note that the GRAST does not interfere with the elevation of the arm, which is almost complete (Fig. 6). This is in line with our biomechanical hypothesis on the behavior of GRAST.

After a rotator cuff tear, inactive muscles tend to atrophy and degenerate into fat, visible on Computerized
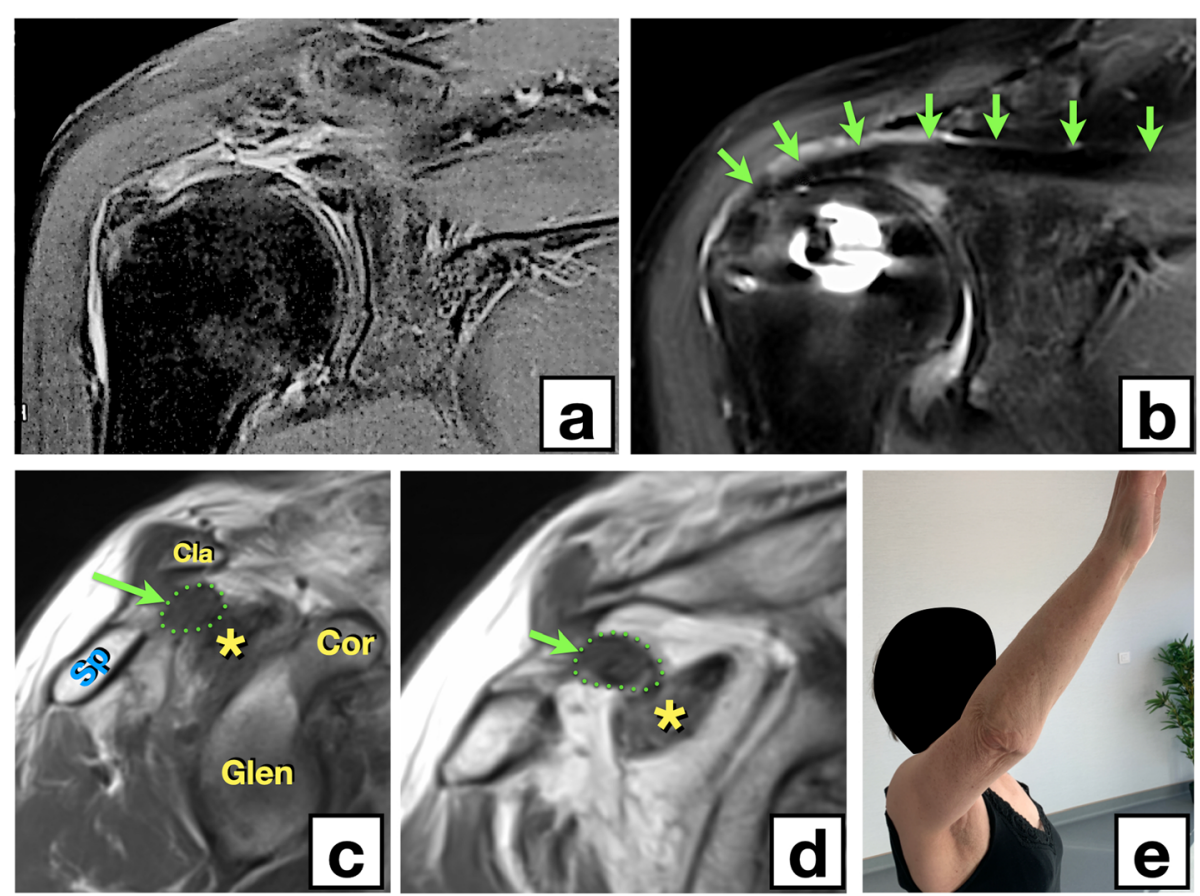

Fig. 6 Clinical case. a Preoperative MRI showing the fully retracted tear of the supraspinatus. b MRI at 1 year postoperatively showing the incorporated GRAST graft (green arrows) from the humerus to the supraspinatus fossa. $\mathbf{c}$, $\mathbf{d}$ Sagittal sections showing the GRAST graft in the supraspinatus fossa (green dotted line). Asterisk: amyotrophic supraspinatus. Sp: Spine of the scapula. Cla: Clavicle. Cor: Coracoid. Glen: Glenoid of the scapula. e Anterior elevation of the arm 
Tomography (CT) and Magnetic Resonance Imaging (MRI) [13]. It would be interesting to evaluate whether restoring continuity between the posterosuperior cuff and the greater tuberosity reactivates the function of an atrophied muscle. Our only clinical case does not allow us to conclude such a recovery, but we have started a clinical study by including patients operated on using the Braided GRAST technique under arthroscopy, by comparing muscle trophicity with imaging of the supraspinatus before and at a distance from surgery, and by evaluating the contractility of the supraspinatus muscle whose continuity with the greater tuberosity has been restored in dynamic ultrasound.

A second limitation is the need to harvest from another anatomical site. As with any graft harvesting, this adds complexity to the technique and increases the risk of specific complications: infection, donor site morbidity, failure of the harvesting, residual pain. This limitation is important as more and more surgeons are overspecialized in shoulder surgery and are therefore unfamiliar with the removal of harmstring tendons. However, the removal of these tendons is commonly performed for cruciate ligament surgery. For surgeons who are used to this procedure, it takes only a few minutes and the scar is short. The rate of infection and specific complications is exceptionally low [7]. The main complication is damage to the infrapatellar branch of the saphenous nerve, generating hypoesthesia distal to the scar. Although frequent, estimated at between 30 and $50 \%$ of patients, this complication is extremely well tolerated [9]. Furthermore, the GRA and ST tendons offer a tissue volume that is much greater than that which the upper limb can provide, which explains their varied use for ligament surgery of the upper limb $[9,18]$. Finally, these tendons regrow between 60 and $80 \%$ of cases in the months following their removal [19].

\section{Conclusions}

In irreparable posterior cuff tears, the tendon defect can be filled by the braided GRAST, which restores the musculo-tendon continuity, and could have a humeral head lowering action and regain at least partially, the motor function of the supra- and infraspinatus and give patients back external rotation. This simple, fast, safe and inexpensive procedure could be an alternative to the proposed treatments, especially in patients not eligible for reverse arthroplasty or tendon transfer. This anatomical study opens the door to clinical experimentation.

\section{Abbreviations}

GRA: Gracilis; ST: Semitendinosus; GRAST: Transplant composed of gracilis and semitendinosus; SS: Supraspinatus; IS: Infraspinatus; APHP: Assistance Publique des Hôpitaux de Paris; CNIL: Commission Nationale de I'Informatique et des Libertés; CT: Computerized Tomography; MRI: Magnetic Resonance Imaging

\section{Acknowledgments}

The authors want to thank the team of the Ecole de Chirurgie du fer à Moulin, 7 rue du Fer à Moulin, 75005, Paris, France, for their availabily and professionnalism.

\section{Authors' contributions}

MP: Project development, Data Collection, Manuscript writing. MLP: Data Collection, Data analysis. MA: Data Collection, Data analysis. MCM: Manuscript editing. AS: Project development, Manuscript writing / editing. MS: Project development, Data Collection, Manuscript writing / editing. All authors have read and approved the manuscript.

\section{Funding}

The research was supported by the authors (design of the study and collection, analysis, and interpretation of data and in writing the manuscript) and the gracious help of the Ecole de Chirurgie du fer à Moulin, 7 rue du Fer à Moulin, 75005, Paris, France, who provided the specimens and the surgical devices.

\section{Availability of data and materials}

The datasets generated and analysed during the current study are not publicly available due to respect of anonymity and medical data but are available from the corresponding author on reasonable request.

\section{Declarations}

Ethics approval and consent to participate

The study was performed in accordance with the ethical standards as laid down in the 1964 Declaration of Helsinki and it's later amendments and the CNIL (Commission Nationale de l'Informatique et des Libertés) and approved under the reference number $13810^{*} 01$. Written informed consent was obtain by the participant included in the study. Written informed consent of using data and material was obtained by the cadaveris specimens before their death.

\section{Consent for publication}

The authors affirm that the participant has consented to the submission and the publication of the article and of images in Fig. 6a, b, c, d, e.

\section{Competing interests}

The authors have no disclosure.

\section{Author details}

'Département de chirurgie orthopédique et traumatologique - Hôpital Saint-Antoine, Assistance Publique - Hôpitaux de Paris (APHP), 184 rue du faubourg Saint Antoine, 75012 Paris, France. ${ }^{2}$ Department of Hand, upper extremity and microsurgery, Prisma Health System, Greenville, SC, USA.

${ }^{3}$ Unité de chirurgie du membre supérieur, Clinique Saint Jean l'Ermitage, 272 avenue Marc Jacquet, 77000 Melun, France.

Received: 2 July 2020 Accepted: 25 March 2021

Published online: 05 April 2021

\section{References}

1. Cerulli G, Placella G, Sebastiani E, Tei MM, Speziali A, Manfreda F. ACL reconstruction: choosing the graft. Joints. 2013;29:459-70.

2. Collin P, Matsumura N, Lädermann A, Denard PJ, Walch G. Relationship between massive chronic rotator cuff tear pattern and loss of active shoulder range of motion. J Shoulder Elb Surg. 2014;23(8):1195-202. https:// doi.org/10.1016/j.jse.2013.11.019.

3. Cowling P, Hackney R, Dube B, Grainger AJ, Biglands JD, Stanley M, et al. The use of a synthetic shoulder patch for large and massive rotator cuff tears - a feasibility study. BMC Musculoskelet Disord. 2020;21(1):213. https:// doi.org/10.1186/s12891-020-03227-z.

4. Gigante A, Bottegoni C, Milano G, Riccio M, Dei GL. Semitendinosus and gracilis free muscle-tendon graft for repair of massive rotator cuff tears: surgical technique. Joints. 2016;04(03):189-92. https://doi.org/10.11138/jts/2 016.4.3.189

5. Gowd AK, Liu JN, Garcia GH, Cabarcas BC, Verma NN. Arthroscopic massive rotator cuff repair and techniques for mobilization. Arthroscopy Tech. 2018; 7(6):e633-8. https://doi.org/10.1016/j.eats.2018.02.013. 
6. Halder AM, Itoi E. Anatomy and biomechanics of the shoulder. Orthop Clin North Am. 2000;31(2):159. https://doi.org/10.1016/s0030-5898(05)70138-3.

7. Hardy A, Casabianca L, Andrieu K, Baverel L, Noailles T. Complications following harvesting of patellar tendon or hamstring tendon grafts for anterior cruciate ligament reconstruction: systematic review of literature. Orthop Traumatol. 2017;103(8):S245-8. https:/doi.org/10.1016/..otsr.2017.09.002.

8. Kapandji. Physiologie articulaire membre supérieur, éditions Maloine, 2005, pp 36-40.

9. Kennedy MI, Peebles LA, Provencher MT, RF LP. Acromioclavicular and Coracoclavicular Ligament Reconstruction for Acromioclavicular Joint Instability. JBJS Essential Surg Tech. 2019;9:e32. https://doi.org/10.2106/JBJS. ST.18.00088

10. Kim JW, Nam DJ. Arthroscopic superior capsular reconstruction by the miniopen modified keyhole technique using an Achilles tendon-bone allograft. Arthroscopy Tech. 2020;9(2):e275-81. https://doi.org/10.1016/..eats.2019.10.007.

11. Lädermann A, Denard PJ, Collin P. Massive rotator cuff tears: definition and treatment. Int Orthop. 2015;39(12):2403-14. https://doi.org/10.1007/s00264015-2796-5.

12. Matthewson $\mathrm{G}$, Coady $\mathrm{CM}$, Wong $\mathrm{IH}-\mathrm{B}$. Rotator cuff reconstruction using fascia Lata patch autograft for the nonrepairable rotator cuff tear. Arthroscopy Tech. 2020;9(1):e123-30. https://doi.org/10.1016/..eats.2019.09.006.

13. Melis B, Nemoz C, Walch G. Muscle fatty infiltration in rotator cuff tears: descriptive analysis of 1688 cases. Orthop Traumatol. 2009;95(5):319-24. https://doi.org/10.1016/j.otsr.2009.05.001

14. Mihata T, Lee TQ, Watanabe C, Fukunishi K, Ohue M, Tsujimura T, et al. Clinical results of arthroscopic superior capsule reconstruction for irreparable rotator cuff tears. Arthroscopy. 2013;29(3):459-70. https://doi. org/10.1016/j.arthro.2012.10.022.

15. Neumann JA, Zgonis MH, Rickert KD, Bradley KE, Kremen TJ, Boggess BR et al. Interposition dermal matrix Xenografts: a successful alternative to traditional treatment of massive rotator cuff tears. Am J Sports Med. 2017; 45(6):1261-8. https://doi.org/10.1177/0363546516683945.

16. Piekaar RSM, Bouman ICE, van Kampen PM, van Eijk F, Huijsmans PE. The subacromial balloon spacer for massive irreparable rotator cuff tears: approximately 3 years of prospective follow-up. Musculoskelet Surg. 2019; 104(2):207-14. https://doi.org/10.1007/s12306-019-00614-1.

17. Senekovic V, Poberaj B, Kovacic L, Mikek M, Adar E, Dekel A. Prospective clinical study of a novel biodegradable sub-acromial spacer in treatment of massive irreparable rotator cuff tears. Eur J Orthop Surg Traumatol. 2013; 23(3):311-6. https://doi.org/10.1007/s00590-012-0981-4.

18. Soubeyrand M, Oberlin C, Dumontier C, Belkheyar Z, Lafont C, Degeorges R. Ligamentoplasty of the forearm interosseous membrane using the semitendinosus tendon: anatomical study and surgical procedure. Surg Radiol Anat. 2006;28(3):300-7. https://doi.org/10.1007/s00276-006-0086-z.

19. Suijkerbuijk MAM, Reijman M, Oei EHG, van Meer BL, van Arkel ERA, Meuffels DE. Predictive factors of hamstring tendon regeneration and functional recovery after harvesting: a prospective follow-up study. Am J Sports Med. 2018;46(5):1166-74. https://doi.org/10.1177/0363546517751660.

20. Tempelaere C, Desmoineaux P, Lespagnol F, Pierrart J, Beaufils P, Pujol N. Surgical repair of massive rotator cuff tendon tears: autologous quadriceps tendon graft versus arthroscopic repair. Orthop Traumatol. 2017;103(3):43540. https://doi.org/10.1016/j.otsr.2016.12.020.

21. Veen EJD, Stevens M, Diercks RL. Biceps autograft augmentation for rotator cuff repair: a systematic review. Arthroscopy. 2018;34(4):1297-305. https:// doi.org/10.1016/j.arthro.2017.10.044

\section{Publisher's Note}

Springer Nature remains neutral with regard to jurisdictional claims in published maps and institutional affiliations.

Ready to submit your research? Choose BMC and benefit from:

- fast, convenient online submission

- thorough peer review by experienced researchers in your field

- rapid publication on acceptance

- support for research data, including large and complex data types

- gold Open Access which fosters wider collaboration and increased citations

- maximum visibility for your research: over $100 \mathrm{M}$ website views per year

At $\mathrm{BMC}$, research is always in progress.

Learn more biomedcentral.com/submissions 